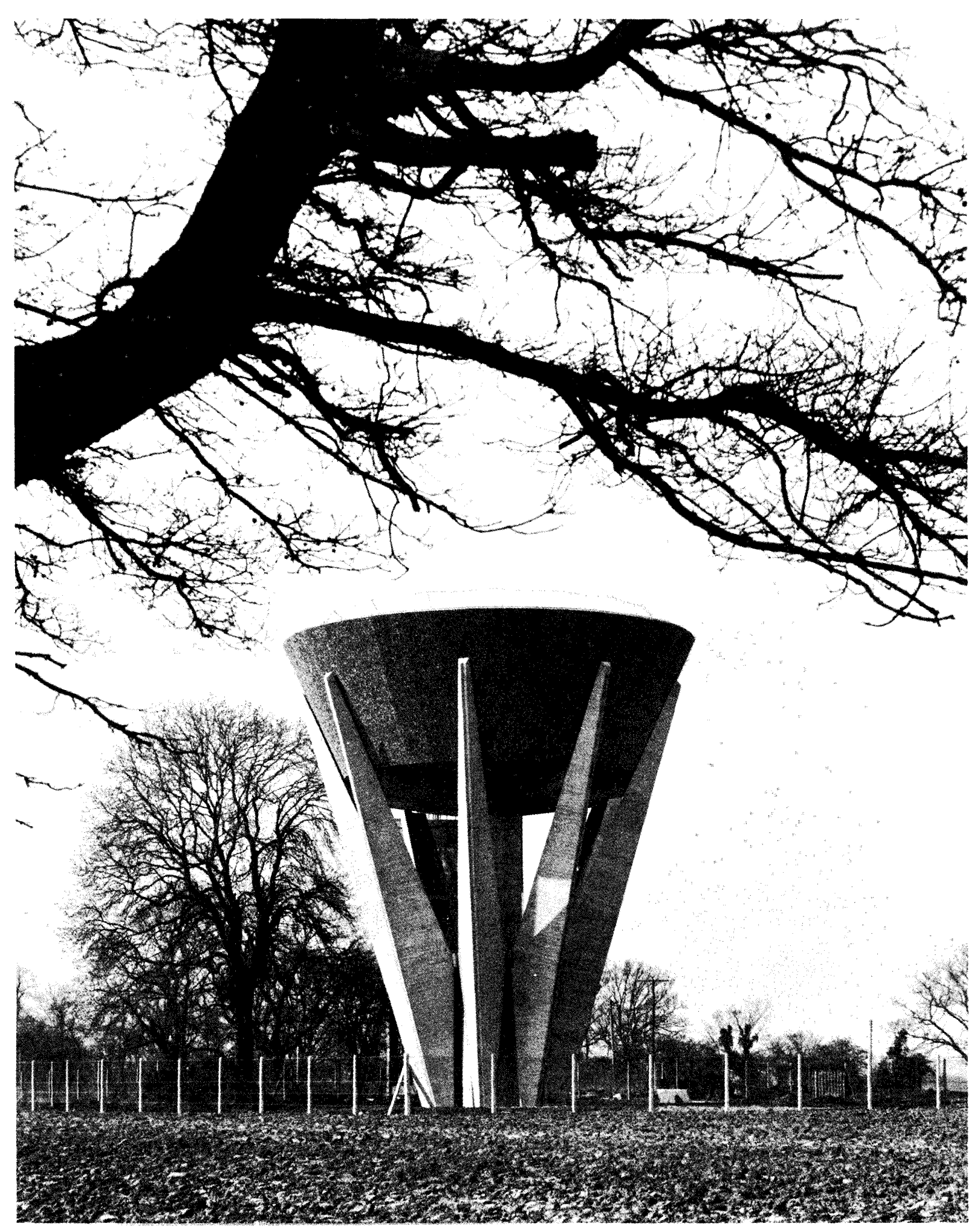

Foto: F. R. Logan, Ltd.

sinopsis

El depósito elevado de agua de Baydon construido para abastecer, entre otras edificaciones, una estación de servicio situada en la autopista $M 4$, tiene $18 \mathrm{~m}$ de altura $y$ 50.000 litros de capacidad.

Está formado por una columna central de hormigón in situ, unas vigas prefabricadas
triangulares -que soportan el depósito de agua propiamente dicho- y unos paneles prefabricados de árido visto para la parte exterior.

La elección de colores neutros, para los mate riales de construcción, contribuyó a no deteriorar el paisaje.

\section{depósito elevado de agua en Baydon Wiltshire - Gran Bretaña}

Edmund Percey Scherrer and Hicks, Arquitectos

$581-27$ 


\section{introducción}

El depósito elevado de agua de Baydon, realizado en sustitución de otra estructura que cumplía, hasta entonces, la misma finalidad pero que se encontraba bastante deteriorada y con pocas posibilidades de reparación, tiene unos 50.000 litros de capacidad y una altura, en el nivel superior del agua, de $18 \mathrm{~m}$ aproximadamente.

Se proyectó para abastecer no sólo a las edificaciones situadas en su entorno, sino también a una estación de servicio cuya construcción estaba prevista en las inmediaciones de la autopista M 4.

De los tres proyectos sometidos a concurso se elegió éste, y para su desarrollo se consultó a los ingenieros hidráulicos del organismo peticionario.

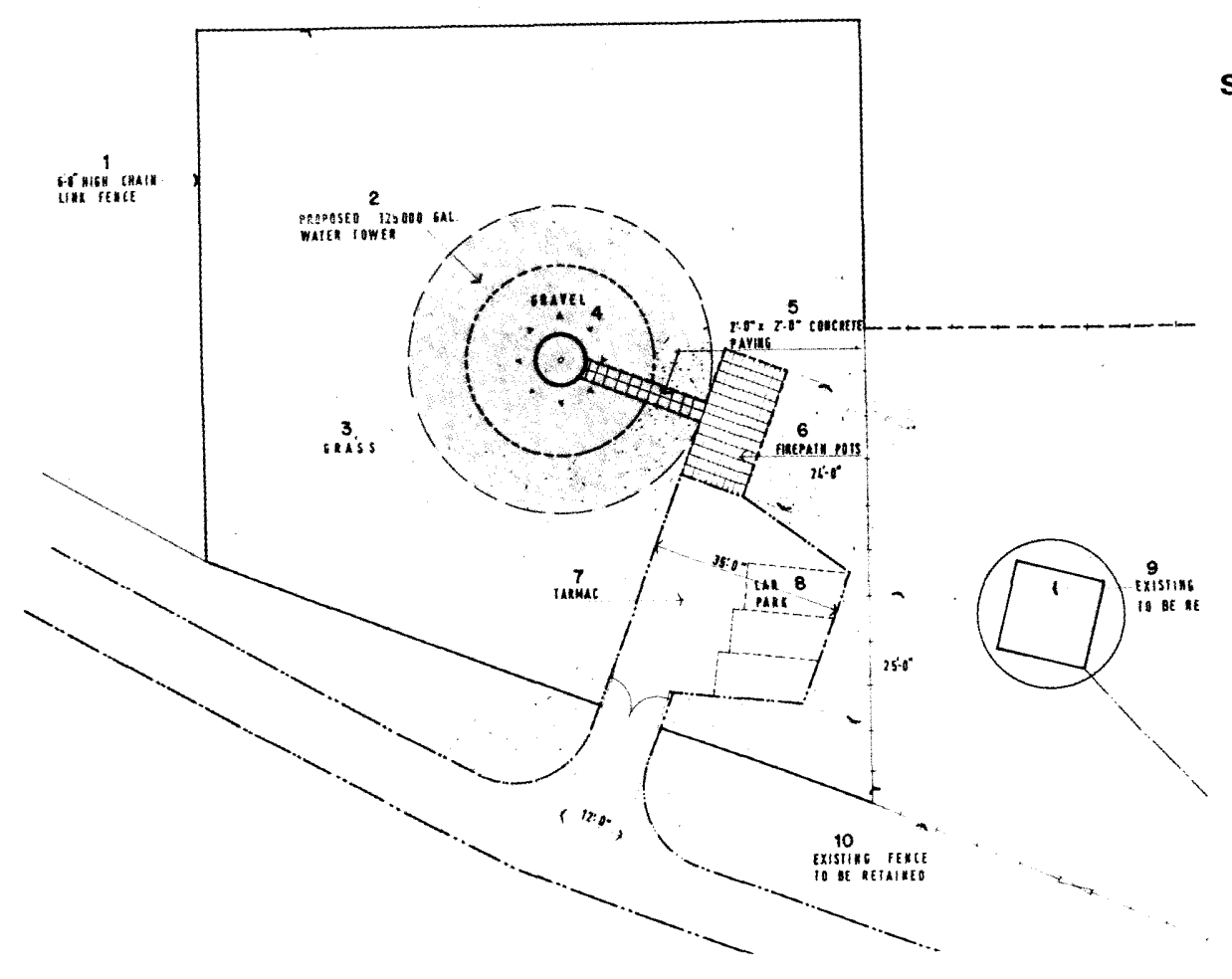

\section{situación}

1.-Límite del recinto. 2.-Depósito de agua para 125.000 galones. 3.Césped. 4.-Grava. 5.-Losetas de hormigón de $0,60 \times 0,60 \mathrm{~m}$. 6.Paso de 7,30 m. 7.-Superficie al. quitranada. 8.-Aparcamiento. 9.Depósito existente. 10.-Valla exis tente.

\section{estudio urbanístico}

El proyecto de esta torre se sometió al examen de la Comisión de Planeamiento de la Ciudad, debido a su situación próxima a la autopista. Las autoridades urbanísticas dieron algunos consejos sobre la construcción de una estructura de cierta altura como ésta, en una zona rural abierta.

La elección de colores neutros para los materiales y la existencia de árboles de gran altura en su entorno ayudó a amortiguar su efecto sobre el paisaje. 

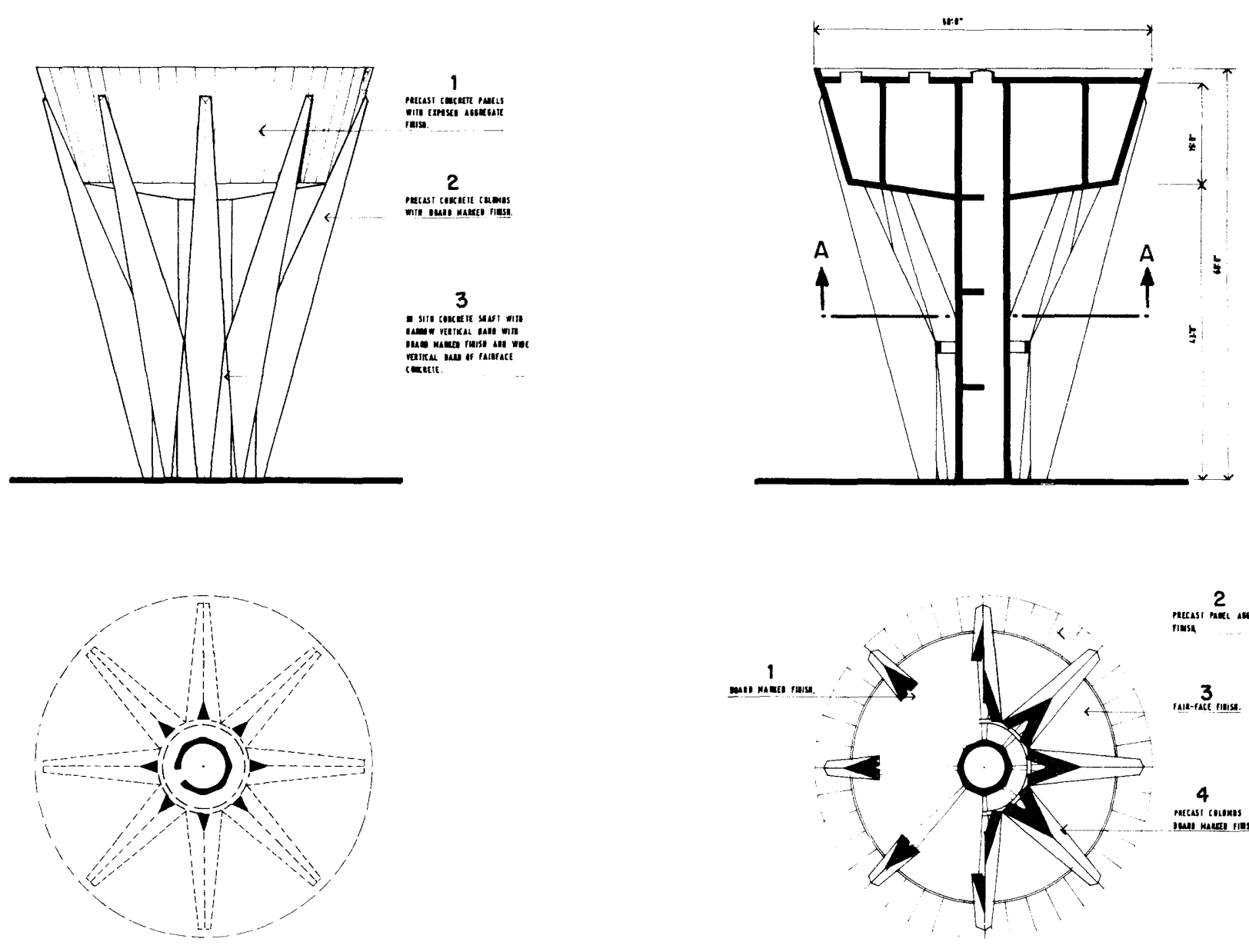

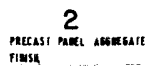

1.-Paneles prefabricados de hor migón con árido visto. 2.-Nervios prefabricados de hormigón. 3.Columna central de hormigón in 1.-Final del nervio. 2.-Paneles
prefabricados. 3.-Acabado. 4.Nervios prefabricados de hormigón. situ.

\section{materiales y métodos de construcción}

Se empleó hormigón in situ vertido de forma continua, cumpliendo las normas previstas en el código vigente de estructuras de contención de agua.

Una columna central de hormigón, de color claro y con su interior hueco, permite el accesc a los dos compartimientos de agua. El acceso a la cubierta, necesario para realizar las tareas de mantenimiento, se hace mediante una claraboya ventilada situada en la parte superior de la columna. Una viga circular vertical separa los compartimientos exterior e interior de agua.

Pilares prefabricados de hormigón, de forma triangular y con el acabado de los bordes bien marcado, soportan el perímetro del depósito de agua. Estos pilares tienen una acanaladura para recoger el agua de lluvia en el vértice del triángulo. El agua llega allí por medio de la junta en ángulo que forman las vigas triangulares.

El exterior del depósito elevado está compuesto por paneles prefabricados de hormigón con árido visto de $5 \mathrm{~cm}$, que se usaron como encofrado permanente del muro interior realizado con hormigón vertido in situ. Juntas verticales acanaladas separan los paneles. 
La cubierta es de asfalto. Una barandilla de cable galvanizado ligero se colocó detrás del borde de la cubierta con objeto de proporcionar seguridad durante las tareas de inspección del depósito.

El proyecto recibió una mención especial de la Concrete Society.

\section{résumé}

CHATEAU D'EAU A BAYDON WILTSHIRE - GRANDE-BRETAGNE Edmund Percey Scherrer and Hicks, architectes

Le château d'eau construit à Baydon pour approvisionner, entre autres bâtiments, une station-service situé sur l'autoroute $M 4$, a $18 \mathrm{~m}$ de haut et peut contenir 50.000 litres.

II est constitué par une colonne centrale en béton sur place, des poutres préfabriquées triangulaires - supportant le château d'eau proprement dit- et des panneaux préfabriqués en agrégats apparents pour la partie extérieure.

Le choix de couleurs neutres, pour les matériaux de construction, a contribué à ne pas détériorer le paysage environnant.

\section{summary}

ELEVATED WATER TANK IN BAYDON WILTSHIRE - GREAT BRITAIN

Edmund Percey Scherrer and Hicks. Architects

The elevated water tank in Baydon, built to supply, among other edifices, a service station located on the M 4 highway, is $18 \mathrm{~m}$ high and holds 50,000 liters.

It is made up by a central column of in situ concrete, triangular prefabricated beams - which support the tank- and prefabricated aggregate panels for the outside.

The choice of neutral colors for the building materials contributed to the preservation of the appearance of the countryside.

\section{zusammenfassung \\ HOCH-WASSERBEHALTER IN BAYDON - WILTSHIRE - GROSS BRETANIEN}

Edmund Percey Scherrer und Hicks, Architekten

Der erhöhte Wasserbehälter in Baydon dient zur Versorgung von verschiedenen Bauwerken, u.a. auch einer Tankstelle an der Autobahn M 4. Er hat eine Höhe von $18 \mathrm{~m}$ und ein Fassungsvermögen von 50.000 Litern.

Er wird von einer zentralen Ortsbetonsäule, vorgefertigten Dreiecksbalken -welche den eigentlichen Behälter tragen- und vorgefertingten Sichtzuschlagsplatten an den Aussenfronten gebildet.

Die Wahl neutraler Farben für die Baustoffe hat dazu beigetragen, dass er sich unauffäl lig der Landschaft anpasst.

\section{publicaciones del PLACAS}

K. Striglat y H. Wipget Drs. Ingenieros

Traducción de Juan Batanero Dr. Ingeniero de Caminos con la colaboración de Francisco Morán Ingeniero de Caminos

Este libro, cuidadosa y magníficamente editado, reúne, quizás, la más completa colección conocida de tablas para placas, por los numerosos casos de vinculación y de carga estudiados y por la abundancia de relaciones de dimensión y de datos ofrecidos, que cubren prácticamente todo el campo de las losas en edificación. Permite desarrollar, con comodidad, rapidez y una aproximación suficiente, los cálculos de dimensionamiento y comprobación, obviando las dificultades que como es sabido, presenta el desarrollo numérico de los métodos de cálculo de estos elementos, evitando enojosas operaciones.

Trata la obra sobre "Zonas de Placas", "Placas sobre apoyos puntuales", "Placas apoyadas en dos, tres y cuatro bordes" y "Placas apoyadas elásticamente", tipos que en la actualidad disponían de una documentación, incompleta o nula, para la determinación de esfuerzos. Los corrimientos de la placa, como valores previos para la determinación de los momentos, han sido obtenidos por medio del Cálculo de Diferencias, método que se ha comprobado como suficientemente satisfactorio, aún en su forma simple, aplicado con un cierto control.

Un volumen encuadernado en tela, de $30,5 \times 23,5 \mathrm{~cm}$, compuesto de 92 págs. Madrid, 1968.

Precios: España, 925 ptas.; extranjero, \$18.50. 